\title{
Effects of antihypertensive drugs on carotid intima-media thickness: Focus on angiotensin II receptor blockers. A review of randomized, controlled trials
}

REVIEW

\author{
Cesare Cuspidi ${ }^{1,2}$ \\ Francesca Negri ${ }^{1,2}$ \\ Valentina Giudici² \\ Anna Capra' \\ Carla Sala ${ }^{3}$ \\ 'Department of Clinical Medicine \\ and Prevention, University of Milano- \\ Bicocca, Milano; ${ }^{2}$ st tituto Auxologico \\ Italiano, Milano; ${ }^{3}$ Thoraco-Pulmonary \\ and Cardiocirculatory Department, \\ University of Milano, Fondazione \\ Policlinico di Milano, Italy
}

\author{
This article was published in the following Dove Press journal: \\ Integrated Blood Pressure Control \\ 26 June 2009 \\ Number of times this article has been viewed
}

Correspondence: Cesare Cuspidi Istituto Auxologico Italiano, Clinical Research Unit,Viale della Resistenza 23, 20036 Meda, Italy

Tel +390362 772436 Fax +390362 772416 Email cesare.cuspidi@unmib.it

\begin{abstract}
Carotid intima-media thickness (IMT) and plaques have been shown to have a strong continuous relationship with cardiovascular (CV) morbidity and mortality; therefore, carotid atherosclerosis, as assessed by ultrasonography, can be regarded as a reliable surrogate end-point for therapeutic interventions. In this survey, we report the results of 16 double blind, randomized, controlled studies comparing: 1) antihypertensive drugs versus placebo/no treatment (five trials including 3,215 patients); 2) different active antihypertensive drug regimens (five trials including 4,662 patients); 3 ) angiotensin-II receptor blockers (ARBs) versus other antihypertensive agents (six trials including 841 patients). Our main findings can be summarized as follows: I) Long-term antihypertensive treatment has a blunting effect on carotid IMT progression, regardless of types of drugs. II) Calcium-channel blockers (CCBs) are more effective than other antihypertensive drugs including diuretics, beta-blockers, and angiotensin converting-enzyme (ACE)-inhibitors in this blunting effect; III) the effect of ARBs compared to other antihypertensive regimens (mostly based on atenolol) on carotid atherosclerosis progression needs to be further elucidated, as a protective effect was demonstrated by some, but not all studies examined. Thus, further studies are needed to clarify the role of ARBs in this therapeutic area.
\end{abstract}

Keywords: ultrasonography, carotid atherosclerosis, antihypertensive drugs, angiotensin II receptor blockers

\section{Introduction}

Numerous studies based on high-definition ultrasound scanning of carotid arteries have demonstrated an association between intima-media thickness (IMT) and cardiovascular (CV) risk factors, ${ }^{1-3}$ preclinical CV alterations such as left ventricular hypertrophy, cerebral white matter lesions, peripheral arterial atherosclerosis, microalbuminuria, coronary calcifications ${ }^{4-7}$ and, more importantly, overt $\mathrm{CV}$ diseases. ${ }^{8}$ In particular, high blood pressure (BP) has been shown to be a major risk factor for carotid IM thickening and plaque progression, ${ }^{9}$ due to the synergistic effect of mechanical stress on the arterial wall and growth/inflammatory factors operating in hypertension.

Prospective studies in population-based samples and selected cohorts of individuals at high risk have demonstrated that diffuse and focal alterations in carotid artery walls are strong predictors of CV morbidity and mortality. ${ }^{10-12}$

Owing to the predictive power of carotid ultrasound alterations, guidelines for the management of arterial hypertension from major International scientific bodies such as the European Society of Hypertension (ESH)/European Society of Cardiology (ESC) submit your manuscript $\mid$ www. dovepress.com

Dovepress 
and World Health Organization (WHO)/International Society of Hypertension recommend carotid examination for a better stratification of total CV. ${ }^{13,14}$

Carotid IMT has been shown to be a valuable surrogate end-point for assessing the antiatherogenic effects of therapeutic interventions, ${ }^{15}$ in particular in clinical trials testing the efficacy of antihypertensive and cholesterol-lowering drugs.

In this paper, we review the studies published in the last decade in which IMT was measured in order to assess the impact of antihypertensive drugs on carotid structure; focusing on the following questions in particular: 1) does antihypertensive treatment affect IMT progression? 2) do different classes of antihypertensive drugs have different antiatherogenic properties? 3) do ARBs have a role in reducing asymptomatic carotid atherosclerosis or in slowing down its progression? Before addressing this issue, however, some more general considerations on the clinical and prognostic value of carotid IMT are needed.

\section{Intima-media thickness as a marker of CV risk}

The refined methodologies now available allow to detect and measure preclinical structural and functional alterations of the CV system. Ultrasonic assessment of the carotid artery structure has attracted considerable interest in this field and is largely applied either for clinical and research purposes. ${ }^{16}$ In the mid 80's, Pioneer studies by Pignoli and colleagues ${ }^{17}$ investigated the correlation of ultrasonic interfaces with anatomical components of the arterial wall; they demonstrated that IM complex, namely the lumen-intima and media-adventitia boundary, which appears as a double-line pattern at the ultrasound examination, provides a reliable measurement of the arterial based on both histological and gross pathological comparisons. Since then, hundreds of cross-sectional studies have been performed in order to assess the prevalence and distribution of carotid atherosclerosis and its association with CV risk factors. ${ }^{1,18}$ In essential hypertensives, a significant increase in IMT has been reported as compared with age-matched normotensive controls, after adjustment for several confounding variables. ${ }^{19}$ Studies in population and hypertensive cohorts have consistently shown that systolic and pulse pressure are significantly correlated to the degree of carotid thickness. ${ }^{20-22}$

A number of prospective trials, including the Atherosclerotic Risk in Communities (ARIC), ${ }^{23}$ the Rotterdam Study, ${ }^{24}$ the Cardiovascular Health Study (CHS), ${ }^{25}$ the European Lacidipine Study on Atherosclerosis (ELSA) ${ }^{26}$ and the
Carotid Atherosclerosis Progression Study (CAPS) ${ }^{27}$ have reported that carotid IMT and/or plaques are strong predictors of coronary events and stroke.

In the ARIC study the relation of carotid IMT with the incidence of coronary heart disease (CHD) was assessed over a 4-7 years follow-up in 7,289 women and 5,552 men aged 45-64 years and free from CHD at baseline. ${ }^{23}$ Incident events were 96 in women and 194 in men; in sexspecific Cox proportional hazards models, the hazard ratio for IMT values $\geq 1 \mathrm{~mm}$ versus $<1 \mathrm{~mm}$ was 5.07 in women (95\% confidence interval [CI]: 3.08-8.36) and 1.85 in men (95\% CI: 1.28-2.69).

The Rotterdam Study investigated the prognostic value of carotid plaques in predicting stroke in a population-based survey including 4,217 asymptomatic subjects aged 55 years or older. ${ }^{24}$ The presence of carotid plaques at six locations of the arteries was assessed at baseline; after an average followup of 5.2 years, 160 strokes had occurred. The presence of carotid plaques, irrespective of their location, increased by $50 \%$ the risk of stroke.

Among the 5,858 elderly participants in the CHS, the incidence of $\mathrm{CV}$ events, in particular the relative risk of myocardial infarction (MI) or stroke, correlated with carotid IMT $(\mathrm{p}<0.001) .{ }^{25}$ The relative risk of MI or stroke adjusted for age and sex in the highest thickness quintile as compared with the lowest one was 3.87 (95\% CI: 2.72-5.51). The association between CV events and IMT remained significant after adjusting for traditional risk factors; the results of separate analyses of MI and stroke paralleled those for the combined end point.

In the ELSA study, including 2,334 patients with uncomplicated hypertension, death, MI, major and all CV events had an increased incidence in the highest carotid IMT quintile and in groups with the greatest number of plaques at baseline. ${ }^{26}$ The risk increase compared to the lowest quintile was about fivefold, when considering IMT, and threefold after adjusting for age, gender, clinical systolic blood pressure (SBP), and treatment.

In the CAPS study common carotid artery (CCA) IMT and vascular risk factors have been evaluated at baseline in 5,056 participants (mean age 50.1 years) and the incidence of stroke, MI, and death was determined prospectively over a mean follow-up period of 4.2 years. ${ }^{27}$ IMT was highly predictive of all end points (eg, hazard rate ratios per $1 \mathrm{SD}$ CCA-IMT increase were 1.43 [95\% CI: 1.35-1.51] for MI, 1.47 [95\% CI: 1.35-1.60] for stroke, and 1.45 [95\% CI: 1.38-1.52] for MI, stroke, or death; $\mathrm{p}<0.0001$ for all). The predictive value of IMT remained significant for MI and 
the combined end point, after adjustment for age, sex, and vascular risk factors.

Overall, these trials indicate that carotid IMT and plaques have a strong continuous relationship with MI, stroke, and $\mathrm{CV}$ death, the relationship remaining significant after adjustment for major traditional risk factors.

\section{Effects of antihypertensive drugs on IMT}

Since the mid 90s, a number of trials have compared the effects of different antihypertensive drugs on carotid IMT and plaque progression in a variety of clinical conditions (ie, CHD, asymptomatic carotid artery disease, diabetes, dyslipidemia, hypertension, and preclinical renal disease). A limited fraction of these studies, however, provided reliable information. Studies evaluating drug effects on IMT progression should follow strict methodological criteria: include enough subjects (at least 100-200 per treatment arm) to detect small but clinically relevant between-treatment differences, have a long-term follow-up (at least $>1$ year) and apply reading protocols minimizing the regression to the mean and readers' bias.

In this review, we describe the results of 16 doubleblind, randomized controlled studies divided in three groups according to the study design comparing: I) antihypertensive drugs with placebo or no treatment (five trials including 3,215 patients); II) active antihypertensive drug regimens based on diuretics, beta-blockers, $\mathrm{CCBs}$ and $\mathrm{ACE}$ inhibitors (five trials including 4,662 patients); III) ARBs versus other antihypertensive agents (six trials including 841 patients). Studies reported in trials comparing antihypertensive drugs versus placebo and trials comparing active antihypertensive drug regimens (Tables 1 and 2) fulfill all the aforementioned criteria; this was not the case for the studies reported in ARBs versus other antihypertensive drugs (Table 3 ), which also included trials with $>40$ patients per treatment arm.

\section{Trials comparing antihypertensive drugs versus placebo}

These trials mostly tested the protective effects of ACEinhibitors on carotid atherosclerosis, as these drugs have been shown to reduce coronary events in various patient groups and to prevent atherosclerosis in animal models.

In the Prevention of Atherosclerosis with Ramipril (PART 2), 617 patients with coronary, cerebrovascular or peripheral vascular disease were randomized to ramipril (5-10 mg daily) or placebo. ${ }^{28}$ Carotid atherosclerosis was assessed at baseline as well as after two and four treatment years: BP was reduced by $6 \mathrm{mmHg}$ systolic and $4 \mathrm{mmHg}$ diastolic in the ramipril compared to the placebo group ( $\mathrm{p}<0.001$ ); no significant difference, however, was found between groups in the changes of CCA far wall thickness or carotid plaque score from baseline to follow-up.

The Prospective Randomized Evaluation of the Vascular Effects of Norvasc Trial (PREVENT) was a multicenter, randomized, placebo-controlled trial designed to test the slowing effect of amlodipine in the progression of early coronary

Table I Randomized controlled trials comparing the effects on carotid IMT of different antihypertensive drugs versus placebo/no treatment with a minimum numerosity of 100 patients per treatment arm

\begin{tabular}{|c|c|c|c|c|c|}
\hline Trial/Setting/Drug & Ref. & Subjects (n) & Primary outcome & $\begin{array}{l}\text { Duration } \\
\text { (years) }\end{array}$ & Results \\
\hline $\begin{array}{l}\text { PART-2 } \\
\text { CHD, cerebrovascular, and periphera } \\
\text { disease ramipril/no-treatment }\end{array}$ & 28 & 617 & IMT changes and plaque score & 4 & No difference \\
\hline $\begin{array}{l}\text { SECURE } \\
\text { Diabetes, vascular disease, ramipril/ } \\
\text { placebo }\end{array}$ & 30 & 732 & IMT changes & 4.5 & $\begin{array}{l}\text { Ramipril more } \\
\text { effective }\end{array}$ \\
\hline $\begin{array}{l}\text { PREVEND } \\
\text { Patients with microalbuminuria, } \\
\text { fosinopril/placebo }\end{array}$ & 31 & 642 & IMT changes & 4 & No difference \\
\hline $\begin{array}{l}\text { BCAPS } \\
\text { Patients with asymptomatic } \\
\text { carotid plaque, metoprolol/placebo }\end{array}$ & 32 & 793 & IMT changes & 3 & $\begin{array}{l}\text { Metoprolol more } \\
\text { effective }\end{array}$ \\
\hline $\begin{array}{l}\text { PREVENT } \\
\text { Sub-study CHD, amlodipine/placebo }\end{array}$ & 29 & 377 & IMT changes & 3 & $\begin{array}{l}\text { Amlodipine more } \\
\text { effective }\end{array}$ \\
\hline
\end{tabular}

Abbreviations: CHD, coronary heart disease; IMT, intima-media thickness. 
Table 2 Randomized controlled trials comparing the effects on carotid IMT of different antihypertensive drugs with a minimum numerosity of 100 patients per treatment arm

\begin{tabular}{|c|c|c|c|c|c|}
\hline Trial/Setting/Drug & Ref. & Subjects (n) & Primary outcome & $\begin{array}{l}\text { Duration } \\
\text { (years) }\end{array}$ & Results \\
\hline $\begin{array}{l}\text { MIDAS } \\
\text { Essential hypertension, israpidine/HC }\end{array}$ & 34 & 883 & IMT changes & 3 & No difference \\
\hline $\begin{array}{l}\text { VHAS } \\
\text { Essential hypertension, verapamil/ } \\
\text { chorthalidone }\end{array}$ & 35 & 498 & IMT changes & 4 & Verapamil more effective \\
\hline $\begin{array}{l}\text { INSIGHT } \\
\text { Essential hypertension, nifedipine/ } \\
\text { co-amilozide }\end{array}$ & 36 & 439 & IMT changes & 4 & Nifedipine more effective \\
\hline $\begin{array}{l}\text { ELSA } \\
\text { Essential hypertension, } \\
\text { lacidipine/atenolol }\end{array}$ & 26 & 2334 & $\begin{array}{l}\text { IMT changes and plaque } \\
\text { progression }\end{array}$ & 4 & Lacidipine more effective \\
\hline $\begin{array}{l}\text { PHYLLIS } \\
\text { Essential hypertension, dyslipidemia, } \\
\text { fosinopril/HCTZ }\end{array}$ & 37 & 508 & IMT changes & 2.6 & Fosinopril more effective \\
\hline
\end{tabular}

Abbreviations: HCTZ, hydrochlorothiazide; IMT, intima-media thickness.

atherosclerosis in 825 patients with angiographically documented CHD ${ }^{29}$ Secondary aim of the study in a subgroup of 377 patients was to investigate the CCB impact on the rate of atherosclerosis progression in carotid arteries. Amlodipine significantly slowed-down carotid atherosclerosis progression during the 36-month study period: the placebo group, indeed, experienced a 33- $\mu \mathrm{m}$ IMT increase, whereas a $126-\mu \mathrm{m}$ decrease was observed in the amlodipine group $(\mathrm{p}=0.007)$.

The Study to Evaluate Carotid Ultrasound changes in patients treated with ramipril and vitamin E (SECURE) was a prospective double-blind trial evaluating the effects of long-term treatment (average follow-up 4.5 years) with ramipril (2.5-10 $\mathrm{mg} /$ day) and vitamin $\mathrm{E}$ on atherosclerosis progression in 732 patients aged $\geq 55$ years, affected by vascular disease or diabetes plus, at least, another risk factor. ${ }^{30}$ The progression slope of the mean maximum carotid IMT was $21.7 \mu \mathrm{m} /$ year in the placebo group, $18.0 \mu \mathrm{m} /$ year in the ramipril $2.5 \mathrm{mg} /$ daily group and $13.7 \mu \mathrm{m} /$ year in the ramipril $10 \mathrm{mg} /$ daily group $(\mathrm{p}=0.033)$, thus indicating that ramipril beneficially affects atherosclerosis progression.

The Prevention of Renal and Vascular ENdstage Intervention Trial (PREVEND) assessed fosinopril and pravastatin

Table 3 Trials comparing the effects carotid IMT of ARBs versus other antihypertensive drugs, with a minimum numerosity of 40 patients per treatment arm

\begin{tabular}{|c|c|c|c|c|c|}
\hline Trial/Setting/Drug & Ref. & Subjects (n) & Primary outcome & $\begin{array}{l}\text { Duration } \\
\text { (years) }\end{array}$ & Results \\
\hline $\begin{array}{l}\text { LAARS } \\
\text { Essential hypertension, losartan/atenolol }\end{array}$ & 40 & 280 & IMT changes & 2 & No difference \\
\hline $\begin{array}{l}\text { SILVHIA } \\
\text { Essential hypertension, irbesartan/atenolol }\end{array}$ & 41 & 108 & IMT changes & 1 & Irbesartan more effective \\
\hline $\begin{array}{l}\text { Ariff et al } \\
\text { Essential hypertension, candesartan/atenolol }\end{array}$ & 42 & 88 & IMT changes & I & $\begin{array}{l}\text { Candesartan more } \\
\text { effective }\end{array}$ \\
\hline $\begin{array}{l}\text { Ichihara et al } \\
\text { Essential hypertension, valsartan/amlodipine }\end{array}$ & 43 & 100 & IMT changes & 1 & No difference \\
\hline $\begin{array}{l}\text { MORE } \\
\text { Essential hypertension and carotid plaque, } \\
\text { olmesartan/atenolol }\end{array}$ & 44 & 165 & IMT and plaque changes & 4 & No difference \\
\hline $\begin{array}{l}\text { Ono et al } \\
\text { Essential hypertension, candesartan/no ARB }\end{array}$ & 45 & 100 & IMT changes & 2 & $\begin{array}{l}\text { Candesartan more } \\
\text { effective }\end{array}$ \\
\hline
\end{tabular}

Abbreviations: ARB, angiotensin-receptor blockers; IMT, intima-media thickness. 
effects on carotid IMT in subjects with increased urinary albumin excretion (UAE; 15 to $300 \mathrm{mg} / 24 \mathrm{~h}$ ). Measurement of IMT was performed at baseline and after four years in 642 subjects randomized to fosinopril $20 \mathrm{mg}$ or matching placebo and to pravastatin $40 \mathrm{mg}$ or matching placebo; ${ }^{31}$ overall IMT progression rate was $37 \pm 6 \mu \mathrm{m}$, no significant differences were found among fosinopril, pravastatin, and placebo.

The Beta-blocker Cholesterol-Lowering Asymptomatic Plaque Study (BCAPS) compared low-dose metoprolol (25 mg daily), fluvastatin (40 mg daily) and placebo effects on carotid IM progression during a 36-month treatment period in 793 subjects with asymptomatic carotid plaques. ${ }^{32}$ At the study end, IMT (mean) progression rate of common carotid was reduced by fluvastatin $(-9 \mu \mathrm{m} / \mathrm{y}$; 95\% CI: -15 to $-3 ; \mathrm{p}=0.002$ ). At both 18 and 36 months, IMT (max) progression in the carotid bulb was reduced by metoprolol $(-58 \mu \mathrm{m} / \mathrm{y}, 95 \% \mathrm{CI}:-94$ to -23 ; $\mathrm{p}=0.004$ and $-23 \mu \mathrm{m} / \mathrm{y}, 95 \% \mathrm{CI}:-44$ to $-3 ; \mathrm{p}=0.014$, respectively), thus reflecting a favorable beta-blocker effect on atherosclerosis progression.

Finally, in a recent meta-analysis including all the above mentioned trials plus four smaller studies, Wang and coworkers have shown that antihypertensive treatment significantly reduced IM thickening rate by $7 \mu \mathrm{m} /$ year compared with placebo $(\mathrm{p}=0.01){ }^{33}$

\section{Trials comparing active antihypertensive drug regimens}

The Multicenter Isradipine Diuretic Atherosclerosis Study (MIDAS) was the first prospective trial investigating this area by comparing the effects of a twice daily dose of isradipine (2.5-5 mg) and hydrochlorothiazide (HCTZ) (12.5-25 mg) in 883 patients with mild to moderate hypertension and maximum IMT of $1.17 \pm 0.20 \mathrm{~mm}(=1170 \pm 200 \mu \mathrm{m}) .{ }^{34}$ The study primary end point, namely the rate of mean maximum IMT progression in 12 carotid sites over three years $(30 \mu \mathrm{m} /$ year $)$, did not differ between the treatment groups $(p=0.68)$. Since patients randomized to $\mathrm{HCTZ}$ achieved significantly lower BP levels than their counterparts, the lack of differences in IMT progression between treatment arms was considered as an indirect evidence of a protective effect of isradipine on the carotid artery wall.

In the Verapamil in Hypertension and Atherosclerosis Study (VHAS) 498 hypertensive patients, randomized to either verapamil (240 mg daily) or chlorthalidone (25 mg daily), underwent carotid ultrasound examinations at baseline and after $3,12,24,36$, and 48 months of treatment. ${ }^{35}$
The primary endpoint for treatment efficacy, namely the IMT change slope over four years (rate of change, $\mu \mathrm{m} /$ year), was significantly different between treatment groups (verapamil $-82 \mu \mathrm{m} /$ year versus chlorthalidone $-37 \mu \mathrm{m} /$ year; $\mathrm{p}<0.02$ ). As the BP-lowering effect of the two randomized treatments was similar, these findings indicate the verapamil is more effective than chlorthalidone in promoting regression of carotid atherosclerosis.

The International Nifedipine GITS Study: Intervention as a Goal in Hypertension Treatment (INSIGHT) assessed common carotid IMT progression in 439 hypertensives randomized to nifedipine $30 \mathrm{mg}$ or co-amilozide (HCTZ $25 \mathrm{mg}$ and amiloride $2.5 \mathrm{mg}$ ) for a four-year follow-up period. ${ }^{36}$ Ultrasonography was performed at baseline, at four months, and subsequently every year. Primary outcome was IMT progression rate (slope of IMT-time regression): this parameter differed between treatment groups either before $(\mathrm{p}=0.002)$ as after $(\mathrm{p}=0.003)$ adjustment for baseline covariates and BP changes. In particular, nifedipine retarded the progression of carotid wall changes as compared to coamilozide, despite similar BP-lowering effects.

The European Lacidipine Study on Atherosclerosis (ELSA), a randomized double-blind trial in 2,334 hypertensive patients, tested the effects of a four-year treatment with lacidipine or atenolol on mean maximum IMT in common carotid arteries and bifurcations. ${ }^{26}$ Yearly IMT progression rate was $14.5 \mu \mathrm{m} / \mathrm{y}$ in atenolol-treated and $8.7 \mu \mathrm{m} / \mathrm{y}$ in lacidipine-treated patients $(\mathrm{p}=0.001)$; plaque progression was significantly less common, and plaque regression was significantly more frequent in the lacidipine group. Clinic BP was similarly reduced by both treatments, whereas 24-hour ambulatory systolic/diastolic BP changes were greater in the atenolol- $(-10 /-9 \mathrm{~mm} \mathrm{Hg})$ than lacidipine-group $(-7 /-5 \mathrm{~mm} \mathrm{Hg})$. A greater efficacy of lacidipine on carotid IMT and plaque progression despite a smaller ambulatory BP reduction, supports an antiatherosclerotic action of lacidipine which is partially independent of the antihypertensive effect.

The Plaque Hypertension Lipid-Lowering Italian Study (PHYLLIS) was designed to test whether: 1) fosinopril (20 mg per day) was more effective than HCTZ (25 mg per day) on carotid atherosclerosis progression; 2) pravastatin (40 mg per day) was more effective than placebo when added to either HCTZ or fosinopril; 3) the ACE inhibitor and statin had additive antiatherosclerotic effects. ${ }^{37}$

Five hundred and eight hypertensive hypercholesterolemic patients with asymptomatic carotid atherosclerosis were randomized to the following treatments: (A) HCTZ, 
(B) fosinopril, (C) HCTZ plus pravastatin, (D) fosinopril plus pravastatin and followed-up for 2.6 years. The primary outcome was the change in mean maximum IMT of far and near common carotid walls and bifurcations bilaterally $\left(\mathrm{CBM}_{\max }\right) \cdot \mathrm{CBM}_{\max }$ significantly progressed $(10 \pm 4 \mu \mathrm{m} /$ year; $\mathrm{p}=0.01)$ in group A compared to the remaining groups; $\mathrm{CBM}_{\text {max }}$ changes in group $\mathrm{B}, \mathrm{C}$, and D were significantly lower than in group A. Clinic and ambulatory BP reductions were not different among groups, whereas total and lowdensity lipoprotein cholesterol decreased by approximately $1 \mathrm{mmol} / \mathrm{L}$ in group $\mathrm{C}$ and $\mathrm{D}$. These results show that both fosinopril and pravastatin exert an antiatherosclerotic action, although they do not provide any evidence about an additive effect of their combination on IMT progression.

\section{$A R B s$ versus other antihypertensive drugs}

Experimental and clinical studies indicate that ARBs exert antiatherogenic antiproliferative effects over and beyond their antihypertensive action. ${ }^{38,39}$ Scarce evidence, however, is available about the properties of these drugs in preventing carotid atherosclerosis progression. Due to the limited number of studies available, also trials with a numerosity of at least 40 patients per treatment-arm and a follow-up of at least one year have been included in this section.

The Losartan Vascular Regression Study (LAARS) investigated the effects of losartan (50 mg once daily) and atenolol (50 mg once daily) on CCA IMT in 280 patients with mild to moderate essential hypertension and right or left CCA IMT between 0.8 and $1.5 \mathrm{~mm}$ at baseline. ${ }^{40}$ Primary end point of the study was the yearly rate of change (YRC) of mean IMT in CCA (CCA-IMTmean) from baseline over two years treatment. Target BP (SBP/diastolic blood pressure $[\mathrm{DBP}]<140 / 90 \mathrm{~mm} \mathrm{Hg}$ ) was achieved by sequentially adding HCTZ $12.5 \mathrm{mg}$ once daily, doubling the dose of the study drug, or adding an open-label CCB, as needed.

Both losartan and atenolol induced comparable reductions in SBP/DBP and CCA-IMT mean over the 24 months period compared to baseline; average YRC was $-38 \pm 04 \mu \mathrm{m} / \mathrm{y}$ for losartan $(\mathrm{p}<0.001)$ and $-37 \pm 4 \mu \mathrm{m} / \mathrm{y}$ for atenolol $(\mathrm{p}<0.001)$.

In the Swedish Irbesartan Left Ventricular Hypertrophy Investigations versus Atenolol (SILVHIA) study 108 hypertensive patients with LV hypertrophy were randomized doubleblind to irbesartan $(\mathrm{n}=52)$ or atenolol $(\mathrm{n}=56)$ treatment for 48 weeks. ${ }^{41}$ Ultrasonographic CCA and echocardiographic examinations were performed at baseline and at the study end. In front of similar blood pressure reductions, CCA IMT tended to decrease with irbesartan $(-10 \pm 100 \mu \mathrm{m}$ from $920 \pm 140 \mu \mathrm{m}, \mathrm{NS})$, whereas it increased with atenolol $(+30 \pm 120 \mu \mathrm{m}$ from $940 \pm 210 \mu \mathrm{m} ; \mathrm{p}=0.018$; with $\mathrm{p}=0.002$ between groups).

Ariff and colleagues compared the effects of a 52-week candesartan-based (8-16 mg daily) and atenolol-based (50-100 mg daily) regimen on CCA and LV structure in 88 hypertensive patients in a randomized, double-blind study. HCTZ (12.5-25 mg/day), felodipine (5-10 mg/day), and doxazosin (4-16 mg/day) were added as required..$^{42}$ Clinic and 24-hour ambulatory BP, left ventricular (LV) mass index, CCA IMT, lumen diameter, IM area, carotid blood flow and distensibility were measured at baseline, at 26 and 52 weeks of treatment. Both candesartan and atenolol similarly reduced IMT and IM area and increased carotid distensibility after 52 weeks. Atenolol-based treatment, however, but not candesartan-based treatment was associated with CCA inward remodeling, as reflected by a reduction of lumen diameter.

Ichihara and colleagues investigated the long-term effects of 24-h ambulatory BP control with amlodipine versus valsar$\tan$ on vascular damage in untreated hypertensive patients. ${ }^{43}$ Pulse wave velocity (PWV), carotid arteries IMT, and 24-h ambulatory BP were determined in 100 untreated hypertensive patients before and after a 12-month treatment.

Amlodipine and valsartan similarly decreased ambulatory BP and PWV; neither drug altered maximum carotid artery IMT, which averaged $920 \pm 50$ and $880 \pm 40 \mu \mathrm{m}$, respectively, at baseline.

The Multicentre Olmesartan atherosclerosis Regression Evaluation (MORE) study, a double-blind trial in hypertensive patients at increased CV risk due to carotid wall thickening and atherosclerotic plaques, compared the effects of a two-year treatment based on either olmesartan or atenolol on CCA IMT and plaque volume (PV) determined by two- and three-dimensional (3D) ultrasound examinations. ${ }^{44} \mathrm{~A}$ total of 165 patients randomized to either olmesartan (20-40 mg/day) or atenolol (50-100 mg/day) underwent carotid ultrasonography at baseline, 28, 52, and 104 weeks of treatment. The primary efficacy outcome was the change from baseline (Delta) in CC-IMT assessed by 2D ultrasound examination; secondary outcomes included Delta in PV assessed by 3D ultrasound and in BP. Olmesartan and atenolol produced comparable significant reductions in CC-IMT; mean Delta IMT was $-90 \pm 15 \mu \mathrm{m}$ for olmesartan and $-82 \pm 14 \mu \mathrm{m}$ for atenolol. Mean Delta PV was $-4.4 \pm 2.3 \mu \mathrm{L}$ and $0.1 \pm 1.5 \mu \mathrm{L}$ in the olmesartan and atenolol group, respectively, without significant betweentreatment differences. In the subgroup of patients with baseline PV greater than or equal to median value $(33.7 \mu \mathrm{L})$, 
significant between-treatment differences existed in Delta PV $(\mathrm{p}=0.023)$, as PV regressed with olmesartan $(-11.5 \pm 4.4 \mu \mathrm{L})$ and was unchanged with atenolol $(0.6 \pm 2.5 \mu \mathrm{L})$, thus suggesting that olmesartan exerts a more protective effect in advanced carotid atherosclerosis. Ono and colleagues evaluated the effects of antihypertensive therapy on NO production, oxidative stress and carotid IMT in 100 hypertensive patients randomized to candesartan $8 \mathrm{mg}$ (plus CCBs, ACE inhibitors, and/or beta-blockers, when needed) or to treatment with all drugs above mentioned other than ARB ${ }^{45}$ Carotid IMT was assessed before and after 12 and 24 months of treatment. Urine levels of 8-hydroxy-2'-deoxyguanosine (8-OHdG), an oxidative stress indicator, and serum levels of NOx, as a marker of NO were measured. BP similarly decreased below 140/90 $\mathrm{mmHg}$ in both groups.

Carotid IMT significantly decreased after 12 and 24 months of treatment in the ARB group, but not in the nonARB group; this decrement was associated with a parallel decrease of 8-OHdG and an increase of NOx levels.

\section{Conclusions}

A solid body of evidence indicates that carotid IM thickening and plaques are important added risks for $\mathrm{CV}$ events in different clinical settings, regardless of BP and conventional risk factors. Thus, carotid atherosclerosis can be regarded as a reliable surrogate end-point for therapeutic interventions. The main findings of our review may be summarized as follows. I) Carotid IMT progression is blunted by long-term antihypertensive treatment: compared with placebo or no treatment, an ACE-inhibitor, ${ }^{28}$ a beta-blocker, ${ }^{31}$ and a $\mathrm{CCB}^{29}$ slightly reduced IMT progression rate in high risk patients with type 2 diabetes, CHD, and vascular disease. II) CCBs are more effective than other antihypertensive drugs in this respect: actively controlled studies show that CCBs retarded IMT progression more effectively than diuretics, ${ }^{34,35}$ betablocker, ${ }^{26}$ and ACE-inhibitor. ${ }^{37}$ The antiatherosclerotic effect of CCBs, shown in these clinical trials, is also supported by the demonstrated efficacy of these agents in various animal models of atherosclerosis. ${ }^{46,47}$ Possible specific mechanisms for the antiatherosclerotic effect of CCBs are inhibited production of reactive oxygen species and reduced expression of adhesion molecules in endothelial cells, and restoration of endothelial function. ${ }^{48}$ III) Limited evidence is available, so far, for ARBs and further studies are needed to clarify role of these drugs in this therapeutic area. In fact, an ARB protective effect against the progression of carotid atherosclerosis was shown by three out of six studies examined, comparing irbesartan versus atenolol, ${ }^{41}$ candesartan versus atenolol, ${ }^{42}$ and
no-ARB antihypertensive therapy. ${ }^{45}$ Minor protective effects favoring ARBs over the beta-blocker atenolol has been also demonstrated in the $\mathrm{LAARS}^{40}$ and MORE ${ }^{44}$ studies.

\section{Disclosure}

The authors report no conflicts of interest in this work.

\section{References}

1. Crouse JR, Toole JF, McKinney WM, et al. Risk factors for extracranial carotid artery atherosclerosis. Stroke. 1987;18:990-996.

2. Folson A, Eckfeldt J, Weitzman S, et al. for the ARIC Investigators. Relation of carotid artery wall thickness to diabetes mellitus, fasting glucose and insulin, body size and physical activity. Stroke. 1994; 25:66-73.

3. Zanchetti A, Hennig H, Baurecht H, et al. Prevalence and incidence of the metabolic syndrome in the European Lacidipine Study on Atherosclerosis (ELSA) and its relation with intima-media thickness. J Hypertens. 2007;25:2463-2470.

4. Cuspidi C, Mancia G, Ambrosioni E, Pessina A, Trimarco B, Zanchetti A. Left ventricular and carotid structure in untreated, uncomplicated essential hypertension: results from the Assessment Prognostic Risk Observational Survey (APROS). J Hum Hypertens. 2004;18:891-896.

5. Bots ML, Van Swieten JC, Breteler MM, et al. Cerebral white matter lesions and atherosclerosis in the Rotterdam Study. Lancet. 1993;341: 1231-1237.

6. Davis PH, Dawson JD, Mahoney LT, Lauer RM. Increased carotid intimal-medial thickness and coronary calcification are related in young and middle-aged adults. The Muscatine study. Circulation. 1999;100:838-842.

7. Cuspidi C, Valerio C, Negri F, et al. Prevalence and correlates of multiple organ damage in referred treated hypertensives: data from the ETODH Study. J Hum Hypertens. 2008;22:801-803.

8. Burke GL, Evans GW, Riley WA, et al; for the ARIC Study Group. Arterial wall thickness is associated with prevalent cardiovascular diseases in middle-aged adults. The Atherosclerosis Risk in Communities (ARIC) study. Stroke. 1995;26:386-391.

9. Zanchetti A, Crepaldi G, Bond MG, et al. Systolic and pulse blood pressure (but not diastolic blood pressure and serum cholesterol) are associated with alterations in carotid intima-media thickness in the moderately hypercholesterolaemic hypertensive patients of the Plaque Hypertension Lipid Lowering Italian Study. PHYLLIS Study Group. J Hypertens. 2001;19:79-88.

10. Toubol PJ, Labreuche J, Vicaut E, Amarenco P; on behalf of the GENIC Investigators. Carotid intima-media thickness, plaques, and Framingham risk score as independent determinants of stroke risk. Stroke. 1999;30:841-850.

11. Simon A, Gariepy J, Megnien JL, Levenson J. Intima-media thickness : a new tool for diagnosis and treatment of cardiovascular risk. JHypertens. 2002;20:159-169.

12. Hodis HN, Mack WJ, LaBree L, et al. The role of carotid arterial intimamedia thickness in predicting clinical coronary events. Ann Intern Med. 1998;128:262-269.

13. Mancia G, De Backer G, Dominiczak A, et al. 2007 Guidelines for the Management of Arterial Hypertension. The Task Force for the Management of Arterial Hypertension of the European Society of Hypertension (ESH) and of the European Society of Cardiology (ESC). J Hypertens. 2007:25:1105-1187.

14. Whitworth JA; World Health Organization, International Society of Hypertension Writing Group. 2003 World Health Organization (WHO)/International Society of Hypertension (ISH) statement on management of hypertension. J Hypertens. 2003;21:1983-1992.

15. Ubels FL, Terpstra WF, Smit AJ. Carotid intima-media: influence of drug treatment and clinical implications. Neth J Med. 1999;55:188-195.

16. Mercuri M, Devi K. Quantitative ultrasonographic evaluation of the carotid arteries in hypertension. J Cardiovasc Risk. 1995;2:27-33. 
17. Pignoli P, Tremoli E, Poli A, Paoletti R. Intimal plus medial thickness of arterial wall: a direct measurement with ultrasound imaging. Circulation. 1986;74:1399-1408.

18. Poli A, Tremoli E, Colombo A, Pignoli P, Paoletti R. Ultrasographic measurement of common carotid artery wall thickness in hypercholesterolemic patients. A new model for the quantitation and follow-up of preclinical atherosclerosis in living human subjects. Atherosclerosis. 1988;7:253-261.

19. Luisiani L, Visonà $\mathrm{A}$, Pagnan $\mathrm{A}$. Non-invasive study of arterial hypertension and carotid atherosclerosis. Stroke. 1990;21:410-414.

20. Bonithon-Kopp C, Scarabin PY, Taquet A, Toubol PJ, Malmejac A, Guize L. Risk factors for early carotid atherosclerosis in middle-aged French women. Arterioscler Thromb. 1991;11:966-972.

21. Ferrieres J, Elias A, Ruidavets JB, et al. Carotid intima-media thickness and coronary artery disease in a low-risk population. J Hypertens. 1999; 17:743-748.

22. Zanchetti A, Bond MG, Hennig M, et al. Risk factors associated with alterations in carotid intima-media thickness in hypertension: baseline data from the European Lacidipine Study on Atherosclerosis. J Hypertens. 1998;16:949-961.

23. Chambless LE, Heiss G, Folson AR, et al. Association of coronary heart disease incidence with carotid arterial wall thickness and major risk factors: the Atherosclerosis Risk in Communities (ARIC) Study, 1987-1993. Am J Epidemiol. 1997;146:483-494.

24. Hollander M, Bots ML, Del Sol AI, et al. Carotid plaque increases the risk of stroke and subgroups of cerebral infarction in asymptomatic elderly: the Rotterdam Study. Circulation. 2002;105:2872-2877.

25. O’Leary DH, Polak JF, Kronmal RA, Manolio TA, Burke GL, Wolfson SK. Carotid-artery intima and media thickness as a risk factor for myocardial infarction and stroke in older adults. $N$ Eng $J$ Med. 1999;340:14-22.

26. Zanchetti A, Bond GM, Hennig M, et al. Calcium antagonist lacidipine slows down progression of asymptomatic carotid atherosclerosis. Principal results of the European Lacidipine Study on Atherosclerosis (ELSA), a randomized, double-blind, long-term trial. Circulation. 2002;106:2422-2427.

27. Lorenz MW, von Kegler S, Steinmetz H, Markus HS, Sitzer M. Carotid intima-media thickening indicates a higher vascular risk across a wide age range. Prospective data from the Carotid Atherosclerosis Progression Study (CAPS). Stroke. 206;37:87-92.

28. McMahon S, Sharpe N, Gamble G, et al. for the PART-2 Collaborative Research Group. Randomized, placebo-controlled trial of the angiotensinconverting enzyme inhibitor, ramipril in patients with coronary or other occlusive arterial disease. J Am Coll Cardiol. 2000;36:438-443.

29. Pitt B, Byington RP, Furberg CD, et al. for the PREVENT Investigators. Effects of amlodipine on the progression of atherosclerosis and the occurrence of clinical events. Circulation. 2000;102:1503-1510.

30. Lonn EM, Yusuf S, Dzavik V, et al; for the SECURE Investigators. Effects of ramipril and vitamin E on atherosclerosis. The Study to Evaluate Carotid Ultrasound changes in patients treated with Ramipril and vitamin E (SECURE). Circulation. 2001;103:919-925.

31. Asselbergs FW, van Roon AR, Hillege HL, et al. Effects of fosinopril and pravastatin on carotid intima-media in subjects with increased albuminuria. Stroke. 2005;36:649-653.

32. Hedblad B, Wiikstrund J, Janzon L, Wedel H, Berglund G. Low-dose metoprolol CR/XL and fluvastatin slow progression of carotid intimamedia thickness main results from the beta-blocker cholesterol-lowering asymptomatic plaque study (BCAPS). Circulation. 2001;103:1721-1726.

Integrated Blood Pressure Control

\section{Publish your work in this journal}

Integrated Blood Pressure Control is an international, peer-reviewed open-access journal focusing on the integrated approach to managing hypertension and risk reduction. Treating the patient and comorbidities together with diet and lifestyle modification and optimizing healthcare resources through a multidisciplinary team approach constitute key
33. Wang JG, Staessen JA, Li Y, et al. Carotid intima-media thickness and antihypertensive treatment. A meta-analysis of randomized controlled trials. Stroke. 2006;37:1933-1940.

34. Borhani NO, Mercuri M, Borhani NO, et al. Final outcome results of the Multicenter Isradipine Diuretic Atherosclerosis Study (MIDAS). JAMA. 1996;276:785-791.

35. Zanchetti A, Agabiti-Rosei E, Dal Palù C, Leonetti G, Magnani B, Pessina A; for the Verapamil in Hypertension and Atherosclerosis Study (VHAS) Investigators. The Verapamil in hypertension and Atherosclerosis Study (VHAS): results of long-term randomized treatment with either verapamil or chlorthalidone on carotid intimamedia thickness. J Hypertens. 1998;16:1667-1676.

36. Simon A, Gariepy J, Moyse D, Levenson J. Differential effects of nifedipine and co-amilozide on the progression of early carotid wall changes. Circulation. 2001;103:2949-2954.

37. Zanchetti A, Crepaldi G, Bond GM, et al. Different effects of antihypertensive regimens based on fosinopril or hydrochlorothiazide with or without lipid lowering by pravastatin on progression of asymptomatic carotid atherosclerosis. Principal results of PHYLLIS- A randomized double blind trial. Stroke. 2004;35:2807-2812.

38. Ferrario CM. Use of angiotensin II receptor blockers in animal models of atherosclerosis. Am J Hypertens. 2002;15:9S-13S.

39. Brenner BM, Cooper ME, de Zeeuw D, et al. Effects of losartan on renal and cardiovascular outcomes in patients with type 2 diabetes and nephropathy. $N$ Engl J Med. 2001;345:861-869.

40. Ludwig M, Stapff M, Ribeiro A, et al. Combination of the effects of losartan and atenolol on common carotid intima-media thickness in patients with hypertension: results of a 2 -year, double blind, randomized, controlled study. Clin Ther. 2002;24:1175-1193.

41. Mortsell D, Malmqvist K, Held C, Kahan T. Irbesartan reduces common carotid artery intima-media thickness in hypertensive patients when compared to atenolol: the Swedish Irbesartan Left Ventricular Hypertrophy Investigations versus Atenolol (SILVHIA) study. J Intern Med. 2007; 26:472-479.

42. Ariff B, Zambanini A, Vamadeva S, et al. Candesartan- and atenololbased treatments induce different patterns of carotid artery and left ventricular remodeling in hypertension. Stroke. 2006;37:2381-2384.

43. Ichihara A, Kaneshiro Y, Takemitsu T, Sakoda M. Effects of amlodipine and valsartan on vascular damage and ambulatory blood pressure in untreated hypertensive patients. J Hum Hypertens. 2006;20:787-794.

44. Stumpe K, Agabiti-Rosei E, Zielinski T, et al. Carotid intima-media thickness and plaque volume changes following 2-year angiotensin II blockade. The Multicentre Olmesartan atherosclerosis Regression Evaluation (MORE) study. Ther Adv Cardiovasc Dis. 2007;1:97-106.

45. Ono H, Minatoguchi S, Watanabe K, et al. Candesartan decreases carotid intima-media thickness by enhancing nitric oxide and decreasing oxidative stress in patients with hypertension. Hypertens Res. 2008;31:271-279.

46. Soma MR, Donetti E, Seregni R, et al. Effect of lacidipine on fatty and proliferative lesions induced in hypercholesterolaemic rabbits. Br J Pharmacol. 1996;118:215-218.

47. Cristofori P, Lanzoni A, Quartaroli M, et al. The calcium-channel blocker lacidipine reduces the development of atherosclerotic lesions in the apoE-deficient mouse. J Hypertens. 2000;18:1429-1436.

48. Taddei S, Virdis A, Ghiadoni L, et al. Effect of calcium antagonist or beta-blockade treatment on nitric oxide-dependent vasodilatation and oxidate stress in essential hypertensve patients. J Hypertens. 2001;19: 1379-1386.

\section{Dovepress}

features of the journal. This journal is indexed on American Chemical Society's Chemical Abstracts Service (CAS). The manuscript management system is completely online and includes a very quick and fair peerreview system, which is all easy to use. Visit http://www.dovepress.com/ testimonials.php to read real quotes from published authors. 